\title{
(6) OPEN ACCESS \\ Chest electrical impedance tomography examination, data analysis, terminology, clinical use and recommendations: consensus statement of the TRanslational EIT developmeNt stuDy group
}

\author{
Inéz Frerichs, ${ }^{1}$ Marcelo B P Amato, ${ }^{2}$ Anton H van Kaam, ${ }^{3}$ David G Tingay, ${ }^{4}$ \\ Zhanqi Zhao, ${ }^{5}$ Bartłomiej Grychtol, ${ }^{6}$ Marc Bodenstein, ${ }^{7}$ Hervé Gagnon, ${ }^{8}$ \\ Stephan H Böhm, ${ }^{9}$ Eckhard Teschner, ${ }^{10}$ Ola Stenqvist, ${ }^{11}$ Tommaso Mauri, ${ }^{12}$ \\ Vinicius Torsani, ${ }^{2}$ Luigi Camporota, ${ }^{13}$ Andreas Schibler, ${ }^{14}$ Gerhard K Wolf, ${ }^{15}$ \\ Diederik Gommers, ${ }^{16}$ Steffen Leonhardt, ${ }^{17}$ Andy Adler, ${ }^{8}$ TREND study group
}

- Additional material is published online only. To view please visit the journal online (http://dx.doi.org/10.1136/ thoraxinl-2016-208357).

For numbered affiliations see end of article.

Correspondence to Professor Dr Inéz Frerichs, Department of Anesthesiology and Intensive Care Medicine, University Medical Center Schleswig-Holstein, Campus Kiel, Arnold-Heller-Str. 3, Kiel 24105, Germany; frerichs@anaesthesie.uni-kiel.de

Received 19 January 2016 Revised 12 July 2016 Accepted 16 July 2016 Published Online First 5 September 2016

\section{CrossMark}

To cite: Frerichs I,

Amato MBP, van Kaam $\mathrm{AH}$ et al. Thorax 2017:72:8393.

\section{ABSTRACT}

Electrical impedance tomography (EIT) has undergone 30 years of development. Functional chest examinations with this technology are considered clinically relevant, especially for monitoring regional lung ventilation in mechanically ventilated patients and for regional pulmonary function testing in patients with chronic lung diseases. As EIT becomes an established medical technology, it requires consensus examination, nomenclature, data analysis and interpretation schemes. Such consensus is needed to compare, understand and reproduce study findings from and among different research groups, to enable large clinical trials and, ultimately, routine clinical use. Recommendations of how EIT findings can be applied to generate diagnoses and impact clinical decision-making and therapy planning are required. This consensus paper was prepared by an international working group, collaborating on the clinical promotion of EIT called TRanslational EIT developmeNt stuDy group. It addresses the stated needs by providing (1) a new classification of core processes involved in chest EIT examinations and data analysis, (2) focus on clinical applications with structured reviews and outlooks (separately for adult and neonatal/paediatric patients), (3) a structured framework to categorise and understand the relationships among analysis approaches and their clinical roles, (4) consensus, unified terminology with clinical user-friendly definitions and explanations, (5) a review of all major work in thoracic EIT and (6) recommendations for future development (193 pages of online supplements systematically linked with the chief sections of the main document). We expect this information to be useful for clinicians and researchers working with EIT, as well as for industry producers of this technology.

\section{INTRODUCTION}

Electrical impedance tomography (EIT) is a radiation-free functional imaging modality invented over 30 years ago. ${ }^{1}$ Scientific and clinical interest in this method is driven by the clinical need for monitoring of lung ventilation and perfusion and for assessment of regional lung function at the bedside. The growing interest is testified by the continuously increasing number of publications on EIT and by the commercial availability of devices from several companies.

This paper was prepared by a working group, collaborating on the clinical promotion of EIT called TRanslational EIT developmeNt stuDy (TREND) group. The group was formed at the meeting 'Chest EIT: Status, Vision and Priorities' (Manchester, UK, 16-17 November 2012), at which leaders of all clinically oriented EIT research groups from North and South America, Europe, Asia and Australia and a representative from each company producing EIT technology were represented. The TREND group consists of pre-eminent researchers and clinical leaders spanning neonatal, paediatric and adult fields of chest EIT. Meetings of this group take place at the annual EIT conferences and congresses of the American Thoracic Society and the European Respiratory Society.

One key concern of the TREND group that resulted in the preparation of this paper was the lack of recommendations for chest EIT examinations, consistent terminology and generally accepted approaches to EIT image analysis and interpretation. The structure of this paper differs from former, rather descriptive reviews. ${ }^{2-11}$ It is based on five core processes that we identified during EIT examination and data analysis (figure 1). These processes involve: (1) execution of EIT measurements, (2) generation of raw EIT images, (3) EIT waveforms and regions-of-interest (ROI), (4) functional EIT images and (5) EIT measures. They are consecutively addressed in the first five sections of the paper. Each section is accompanied by an electronic online supplement (EOS) with detailed figures, definitions, recommendations and examples. A separate online supplement with the definitions of EIT-related terms is provided.

The last part of the article focuses on the clinical use of EIT in adult, neonatal and paediatric patients. The major target populations are mechanically ventilated patients, typically requiring intensive care therapy, and pulmonology patients suffering from chronic lung diseases. Two supplements linked to these clinical sections provide summaries and lists of clinical issues benefiting from EIT-guided clinical decisions. Finally, we propose 
Figure 1 Schematic presentation of the chest EIT examination and data analysis. The drawings, examples of EIT images and EIT measures illustrate the different steps involved. The images were generated using the GREIT image reconstruction algorithm from data acquired in a healthy adult subject with the Goe-MF II EIT device (CareFusion, Höchberg, Germany). (These images as well as the data shown in subsequent figures originate from examinations approved by the institutional ethics committees and acquired with written informed consent.) ARDS, acute respiratory distress syndrome; EIT, electrical impedance tomography; rel. $\Delta \mathrm{Z}$, relative impedance change; $\mathrm{Gl}$, global inhomogeneity index; CoV, centre of ventilation; PEEP, positive endexpiratory pressure; ROP, regional opening pressure; RVD, regional ventilation delay.

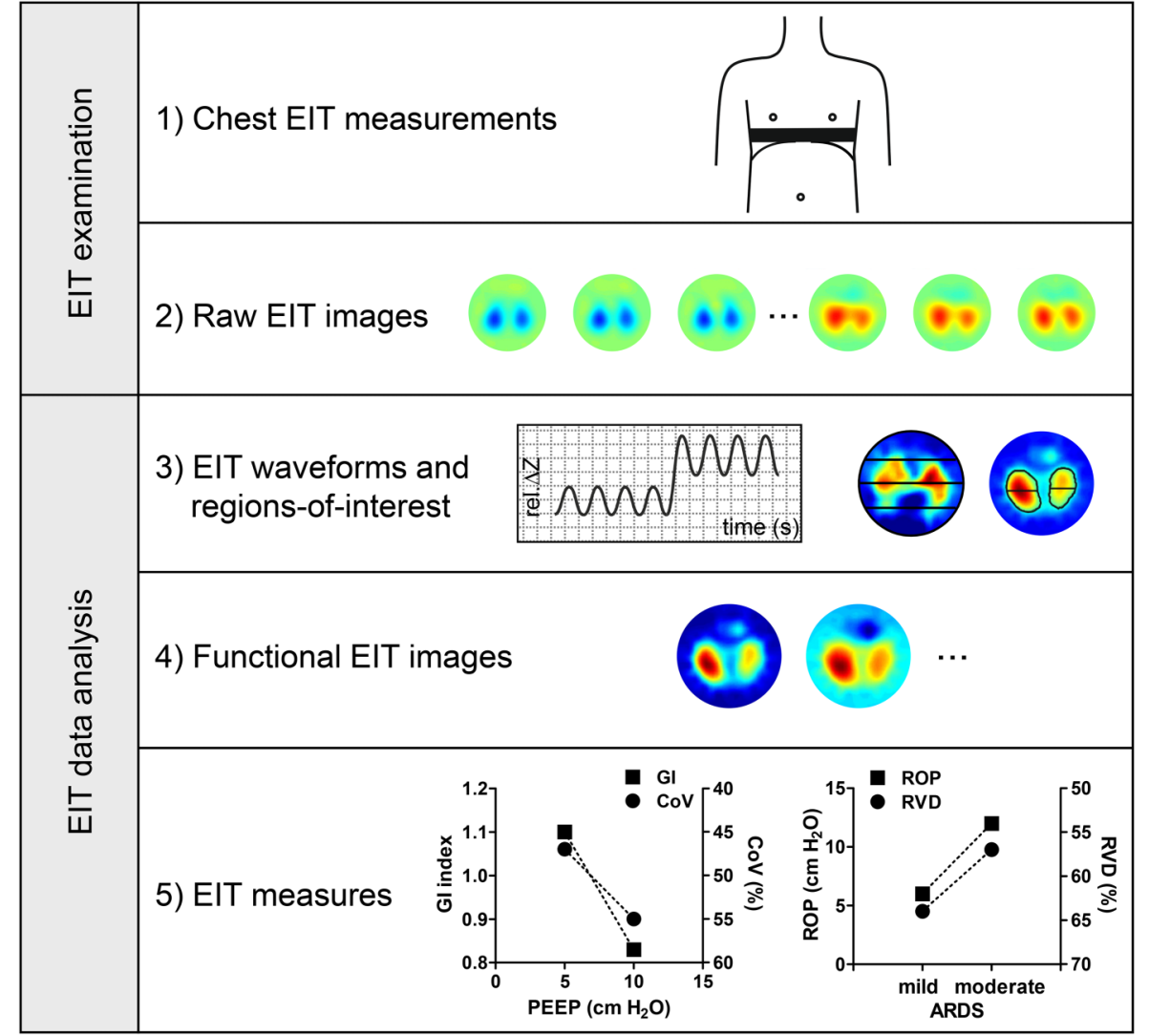

recommendations for the future research and development of EIT presented in detail in the last EOS. All nine online supplements contain comprehensive lists of references.

Our paper is the result of a joint effort of EIT experts based on extensive literature search and, their expertise and experience with this medical technology. It is neither a health technology assessment nor a conventional systematic review. Nonetheless, we believe that it will become a reference document that reviews main achievements and outlines recommendations for clinical use, describes how errors and misinterpretations in EIT data acquisition and analysis can be avoided and facilitates sharing and comparison of research and clinical results.

We expect our consensus document to be relevant to current clinical users of EIT (adult and neonatal/paediatric intensivists), potential new users (adult and paediatric pneumologists) and producers of EIT technology.

\section{EXECUTION OF EIT CHEST MEASUREMENTS}

EIT examinations require the placement of electrodes on the chest circumference, positioned to be sensitive to the phenomena of interest. Electrodes are either placed individually with equal spacing or are integrated into electrode belts or stripes, which render the application user-friendly. Several EIT devices use 16 electrodes, although systems with a higher and lower number of electrodes have also been developed. The electrodes are typically placed in one transverse plane, although oblique placement has also been described. Large chest wounds, multiple chest tubes, non-conductive bandages or conductive wire sutures may preclude or affect the measurements.

The location of the electrode plane impacts the findings; ${ }^{12-15}$ thus, comparability of examinations performed on separate occasions requires electrode locations to be the same. It is not recommended to place the electrodes lower than the sixth intercostal space because the diaphragm may periodically enter the measurement plane. ${ }^{13}$ Posture $^{1416-19}$ and type of ventilation ${ }^{20-25}$ affect the findings. Specific ventilation manoeuvres, mechanical ventilation mode and settings, etc should be recorded to ease the interpretation of EIT findings.

During an EIT examination, very small alternating electrical currents are applied through pairs of electrodes while the resulting voltages are measured on the remaining electrodes. The most widespread spatial pattern of current applications and voltage measurements is through adjacent electrode pairs. Other patterns of current applications and voltage measurements are increasingly used and can be expected to replace the adjacent pattern because they offer technical advantages. Further information on the execution of EIT measurements is provided in EOS 1.

\section{RAW EIT IMAGES}

The set of EIT data acquired during one cycle of current applications and voltage measurements is typically called frame. One EIT data frame contains the information necessary to generate one raw image. The number of frames (or raw images) acquired per second corresponds with the EIT scan rate. Current EIT devices offer maximum scan rates of about 50 images/s allowing the assessment of lung function under dynamic conditions.

EIT is sensitive to periodic and non-periodic changes in electrical tissue conductivity in a slice with a vertical thickness roughly half the chest width. ${ }^{26}$ An increase in intrapulmonary gas volume decreases conductivity, while increased blood or fluid volume or disruption of cellular barriers raise it.

Image reconstruction is the process of generating raw EIT images from the measured voltages, typically of a twodimensional slice through the electrode plane. ${ }^{27}$ Time-difference 
EIT image reconstruction calculates images of the change in tissue properties between a baseline (reference) measurement frame and the current frame. Time-difference imaging is well suited to trace time-varying physiological phenomena like lung ventilation and perfusion. Two other imaging modalities are active areas of research, but currently insufficiently robust for chest EIT: (1) frequency-difference imaging, sensitive to the difference in tissue properties between two stimulation frequencies at a given time and (2) absolute imaging, which calculates images of the properties at a given time (ie, not just relative impedance changes).

An ideal reconstruction algorithm should guarantee uniform amplitude response, small and uniform position error, small ringing artefacts, uniform resolution, limited shape deformation, high resolution and exhibit small sensitivity to electrode and boundary movement. ${ }^{28}$ The images are either round or, in newer algorithms, their contour reflects the anatomical form of the chest. Development of new algorithms is an active field in EIT research with advances in image quality achieved by using, for example, a priori anatomical information.

The orientation of EIT images is identical to the images generated by established imaging modalities like CT with the right chest side on the left side of the image and with anterior at the top. The colour coding of EIT images depends on the choice of the baseline frame and is not unified (for examples, see EOS 2).

\section{EIT WAVEFORMS AND ROI}

EIT data analysis is based on the EIT waveforms that are generated from a series of raw EIT images in individual image pixels. ROI can be defined in an image (minimum size being one image pixel). In each ROI, the waveform over time displays the shortterm and long-term changes in local electrical impedance resulting from various physiological or pathological effects. Periodic signal fluctuations are induced by ventilation or by heart action and lung perfusion (figure 2). Digital frequency filtering is often used in EIT data analysis to isolate these periodic phenomena. A non-periodic change may be caused, for example, by an overall increase in gas volume induced by raising the positive end-expiratory pressure (PEEP) during mechanical ventilation. $^{29-31}$

The magnitude of the impedance changes associated with spontaneous breathing or mechanical ventilation is approximately one order of magnitude larger than the changes induced by heart action and lung perfusion. ${ }^{32}$ Besides physiological and pathological effects, EIT waveforms may also display artefacts originating from, for example, body movement ${ }^{33}$ or interference with some medical devices. ${ }^{34}$ Modern EIT devices have somewhat improved robustness to interference. The artefacts can often be eliminated by adapting the EIT data acquisition parameters or by signal postprocessing.

EIT images show not only the lungs but the whole chest cross-section. To increase the sensitivity of EIT data analysis, ideally only waveforms originating from lung regions should be analysed. The border between the pulmonary and nonpulmonary tissue is blurred in EIT images. Therefore, several approaches have been proposed to determine ROIs representing the lungs. 3536

EIT lung ROIs are mostly functionally identified as regions where ventilation-related impedance changes occur. If this approach is applied, lung regions with absent or small

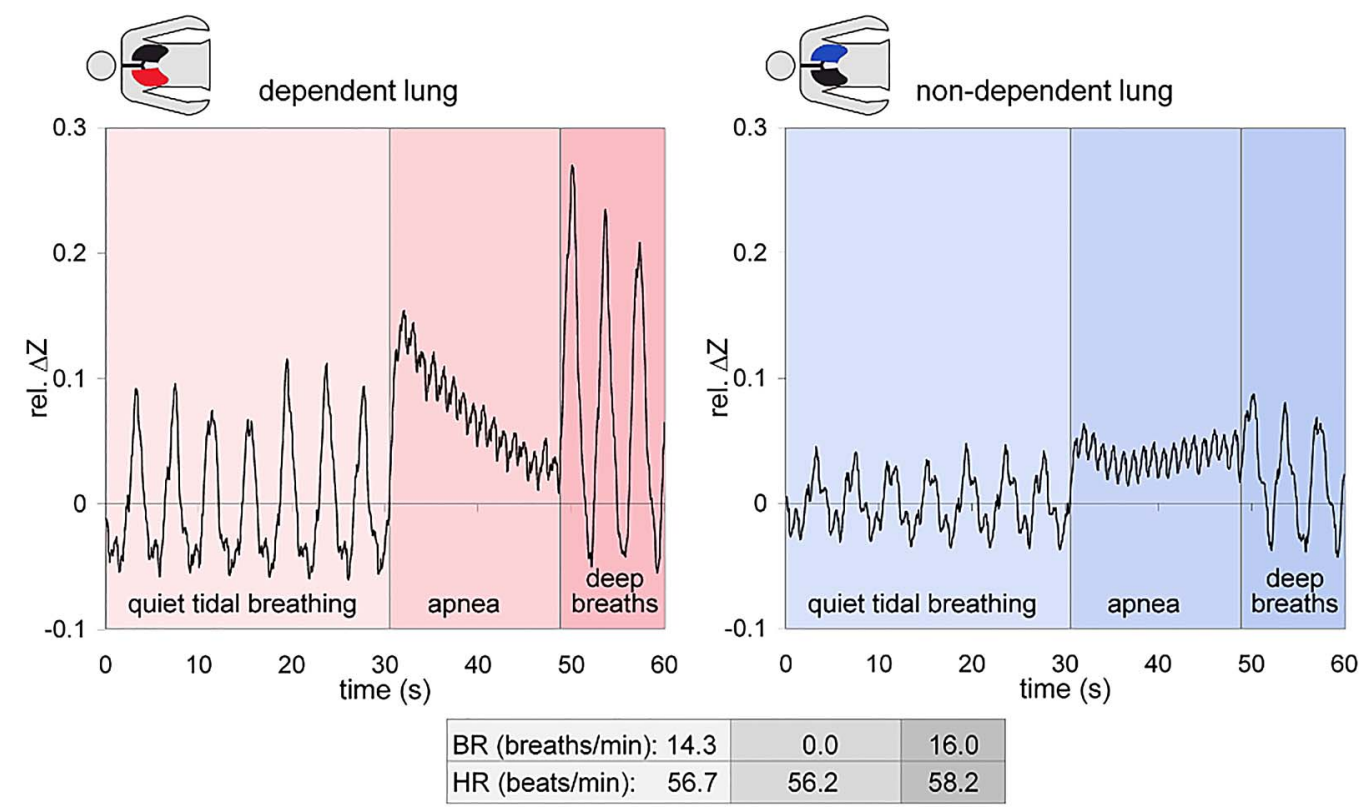

Figure 2 Electrical impedance tomography (EIT) waveforms simultaneously registered in one image pixel in the dorsal region of the dependent (left) and in another pixel in the dorsal region of the non-dependent lungs (right) in a healthy man aged 43 years lying on his right side. The raw data were obtained using the Goe-MF II EIT device (CareFusion, Höchberg, Germany) and reconstructed with the GREIT algorithm. During the first $30 \mathrm{~s}$, the subject was breathing quietly, then he was instructed to hold his breath for $20 \mathrm{~s}$ after tidal inspiration, finally he took three deep breaths. The periodic ventilation-related changes of the EIT signal, given as relative impedance change (rel. $\Delta \mathrm{Z}$ ), are higher than those associated with the cardiac action. (The latter are best discernible during the apnoea phase.) The tidal changes in rel. $\Delta Z$ during the first and the third phases of this measurement are higher in the dependent than in the non-dependent lung reflecting the physiologically known higher ventilation of the dependent lung regions in adult subjects spontaneously breathing at the functional residual capacity level. During the apnoeic phase, the EIT signal falls continuously in the dependent lung due to local gas volume loss caused by the continuing gas exchange. This is not observed in the non-dependent lung. The changes in rel. $\Delta Z$ synchronous with the heartbeat are of comparable amplitude in both pixels. The breathing rate (BR) and heart rate (HR) in each of the three examination phases given in the lower part of the figure were derived from frequency filtering of the EIT signal. 
ventilation-related impedance changes (eg, atelectasis, pleural effusion or pneumothorax) may be missed. If unaccounted for, this may impact subsequent analyses, for example, by showing less ventilation heterogeneity, than present.

The other motivation for ROI-based analysis of EIT data is to characterise the spatial heterogeneity of lung ventilation. For this application, arbitrary ROIs, like image quadrants or layers are used. ${ }^{24}$ 37-39 These are either applied to the whole image or are combined with a previously defined lung ROI. Further details can be found in EOS 3.

\section{FUNCTIONAL EIT IMAGES}

Functional EIT images are generated from series of raw images and the corresponding pixel EIT waveforms, by use of appropriate mathematical equations in each image pixel. All calculated values are then plotted (or image colour-coded) in the respective pixels. Various functional EIT measures have been proposed and used to quantify and characterise regional lung ventilation (and perfusion). These are briefly addressed here but described in detail in EOS 4.

Today's high EIT scan rates allow precise identification of the tidal peak-to-trough changes in the pixel EIT waveforms and generation of functional EIT images proportional to the local tidal volume $\left(\mathrm{V}_{\mathrm{T}}\right) .^{25} \quad{ }^{37} \quad{ }^{40} \quad{ }^{41}$ Identification of pixel end-expiratory minima before and after a change in ventilator settings (eg, in PEEP) creates a functional EIT image of the local changes in end-expiratory lung volume (EELV). ${ }^{29}$ If EIT data are acquired during the forced full expiration then the calculation of the electrical impedance change within the first second of the forced exhalation will image the distribution of local $\mathrm{FEV}_{1}{ }^{42}$

The analysis of the dynamic characteristics of pixel EIT waveforms enables the assessment of the non-linearity of local filling and emptying of the lungs and creation of functional EIT images showing the spatial distribution of this non-linear behaviour. $^{43}$ If EIT examination is performed during a stepwise inflation or deflation of the lungs then fitting of mathematical functions to pixel EIT waveforms may be used to calculate and image local respiratory time constants. ${ }^{44}$

Combination of pixel EIT waveforms with other simultaneously registered signals like the airway pressure allows the generation of pixel pressure-volume curves ${ }^{45} 46$ and generation of functional images showing, for example, regional lung opening and closing ${ }^{47}$ or regional respiratory system compliance $\left(\mathrm{C}_{\mathrm{rs}}\right){ }^{48}$

Several types of functional images can be generated from a single EIT measurement. They address different aspects of regional lung function, thus, the combination of these findings allows a more thorough interpretation of EIT data.

\section{EIT MEASURES}

Functional EIT images display the calculated functional measures with the highest spatial resolution available. Based on these images, it is desirable to create quantifiable clinically relevant measures to assess the present state of ventilation distribution and its trends. Images and numeric values are complementary.

Quantitative EIT measures can be divided into three groups. The first group has the same functional measures as the ones used to generate functional EIT images, only the pixel values of these measures are averaged (or summed) across the whole image or its sections. For instance, the sum of tidal impedance changes in all image pixels provides an estimate of regional $V_{T}$ in the studied chest slice.

The second group aims at characterising the spatial distribution of ventilation. One subgroup describes the overall degree of spatial heterogeneity of ventilation. Examples are the global inhomogeneity index ${ }^{36} 4049$ or the coefficient of variation, ${ }^{36} 4250$ calculated from the maps of tidal impedance variation. Another subgroup describes the orientation of the spatial distribution of functional measures, usually in the anteroposterior direction. This direction is clinically relevant when patients are examined in the supine position, where it corresponds to the gravity vector. The simplest measure is the anteroposterior (upper-to-lower) ventilation ratio, calculated as the ratio between the sum of tidal impedance changes in the anterior and posterior halves of the functional image or the lung ROI within it. ${ }^{51}$ Alternatively, the anterior and posterior fractions (percentages) of ventilation are calculated. ${ }^{24}$ Fractions of ventilation can also be computed in larger number of smaller ROIs spanning the whole image in the anteroposterior direction and used to create ventilation profiles. ${ }^{37} 5253$ The centre of ventilation, frequently used to describe the ventilation distribution with relation to the chest diameter, is derived from such profiles. $^{20} 375354$

The third group includes examination-specific measures. Examples are measures of perfusion via an infusion of conductivity-contrasting bolus, ${ }^{55}$ or measures that are derived from the EIT data registered in parallel with other signals, mostly airway pressure. Such measures aim at characterising regional $\mathrm{C}_{\mathrm{rs}}$ under quasistatic ${ }^{45} 56$ but mostly dynamic conditions. ${ }^{57} 58$ The high scan rates allow the assessment of intratidal changes in regional $\mathrm{C}_{\mathrm{rs} .}{ }^{38}$ Another EIT measure of respiratory mechanics is the regional respiratory time constant. ${ }^{4459}$

Temporal heterogeneity of ventilation can be characterised by calculating the phase shifts in regional ventilation ${ }^{60}$ or ventilation delay index. ${ }^{61}$ Regional expiration times needed to exhale specified percentages of regional gas volumes can also be derived from EIT waveforms. ${ }^{42} 6263$ Further details on EIT measures are presented in EOS 5.

The taxonomy of EIT terms with clinical user-friendly definitions and explanations is provided in EOS 6.

\section{CLINICAL USE OF EIT IN ADULT PATIENTS}

Three general uses of thoracic EIT have been promising in adult patients: (a) monitoring of mechanical ventilation, (b) monitoring of heart activity and lung perfusion and (c) pulmonary function testing. The validity and reproducibility of EIT findings is derived from several experimental and clinical studies comparing EIT with reference techniques like CT, ${ }^{61}$ 64-66 single-photon emission CT, ${ }^{67}$ positron emission tomography, ${ }^{68}$ vibration response imaging, ${ }^{69}$ inert-gas washout ${ }^{70}$ and spirometry. ${ }^{14} 3071$

EIT examinations over time often provide unique clinical information difficult to obtain by other technologies at the bedside. With almost no side effects, EIT allows the sensitive and prompt assessment of lung characteristics over the course of disease and treatment.

\section{Monitoring of mechanical ventilation}

The need for monitoring regional effects of mechanical ventilation is based on our understanding of the direct damage inflicted by the ventilator on the fragile lung. Protective ventilation has been increasingly demanded inside and outside intensive care units to prevent/minimise ventilator-associated lung injury. Global measures of oxygenation or respiratory system mechanics, traditionally used as references to adjust mechanical ventilation, may produce misleading information by 'averaging' opposite pathological phenomena (eg, tidal recruitment and overdistension) in different lung units. This underlines the need for regional functional lung monitoring. 
EIT can generate regional measures characterising this heterogeneous behaviour of the lung tissue under dynamic conditions that might be used in guidance of mechanical ventilation. Experimental studies showed that regional responses of the lung to a 'recruiting manoeuvre,, $37{ }^{72} \mathrm{PEEP}^{29} 4157$ fraction of oxygen $^{54}$ or $\mathrm{V}_{\mathrm{T}}$ adjustment ${ }^{52}$ can be continuously obtained by EIT. The more recent clinical data suggest the promising use of fast-response EIT parameters to titrate protective PEEP/ $\mathrm{V}_{\mathrm{T}} \mathrm{com}$ binations, or to assess the potential for lung recruitment in patients with acute respiratory distress syndrome (ARDS). These measures have most often been derived from the decremental PEEP-titration manoeuvre. ${ }^{73-75}$ Figure 3 shows an example patient examination during this manoeuvre. By sequentially measuring the EIT-derived regional $\mathrm{C}_{\mathrm{rs}}$, it is possible to quantify the amounts of tissue that (a) recollapse during the trial, excluding them from ventilation and (b) are brought back to adequate ventilation, previously impaired by hyperdistension.

The side effects of mechanical ventilation are aggravated by heterogeneities in lung properties or in pressure transmission caused by disease, ageing or gravity forces. Major heterogeneities in regional ventilation in diseases like ARDS, ${ }^{44} 66$ COPD, ${ }^{42}{ }^{62}$ lung cancer ${ }^{76}$ or cystic fibrosis ${ }^{77}$ can be traced by EIT. The effects of ageing can also be detected. ${ }^{16} 42$ The capability of EIT to determine gravity-dependent changes has been confirmed in studies where human subjects were exposed to weightlessness $^{43}$ or posture changes. ${ }^{14}{ }^{16}$ Posture-dependent changes in ventilation can be traced by EIT in a clinical setting ${ }^{78}$ as well and used to monitor the patient's response to rotation. These and other clinical studies, although often with relatively low numbers of patients, corroborate the perspective of realtime monitoring of lung function heterogeneities by EIT at the bedside, potentially helping to optimise lung protection.

A few clinical studies imply the usefulness of EIT monitoring during assisted mechanical ventilation where spontaneous breathing activity is combined with gas delivery by the ventilator. EIT can determine regional $\mathrm{C}_{\mathrm{rs}}$ during this ventilation ${ }^{31}$ and uncover potentially harmful excessive regional $\mathrm{V}_{\mathrm{T}}$, even in the context of a 'protective' $\mathrm{V}_{\mathrm{T}}$ delivered to the whole lung. ${ }^{22}$ The detection of this 'pendelluft' phenomenon by EIT is shown in figure 4.

A relevant feature of EIT is its ability to identify various adverse events during mechanical ventilation. This would enable early therapeutic intervention and/or reduce the need for other diagnostic methods. Experimental studies confirmed the detection of pneumothorax ${ }^{39} 79$ or derecruitment, for example, after suctioning. ${ }^{61} 80$ Clinical data are rare: there exist studies in patients with pleural effusion, which only confirm the ability to detect impedance changes related to fluid removal, ${ }^{81}$ but not prospectively identify pleural effusion development. The ability of EIT to detect one-sided ventilation with selective intubation has been validated in patients. ${ }^{82}$

Our perspective is that EIT will become a standard monitoring technique for personalised protective mechanical ventilation and optimised ventilator adjustments, increasing patient safety
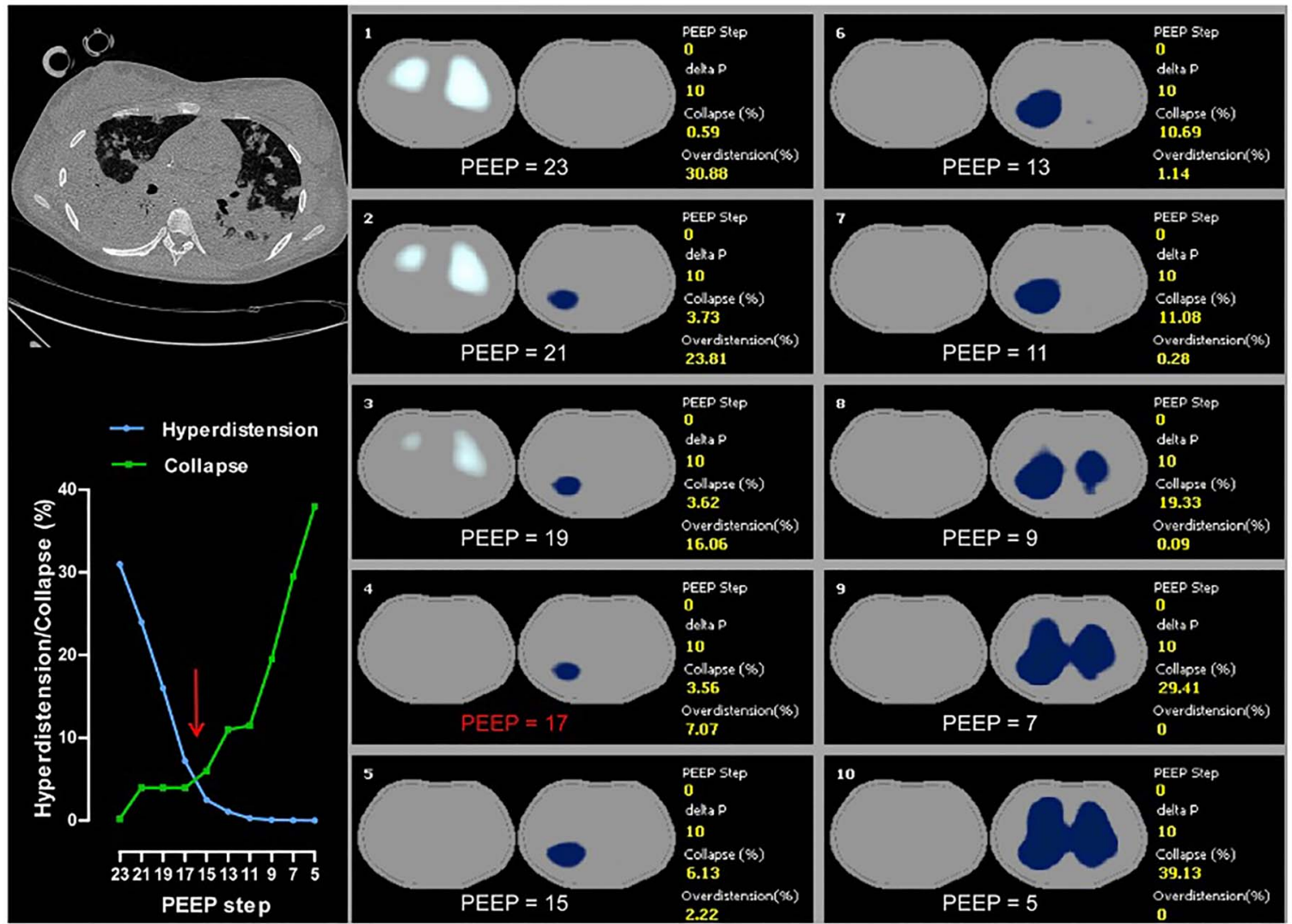

Figure 3 An adult mechanically ventilated patient examined by electrical impedance tomography (EIT) (Enlight, Timpel, Sao Paulo, Brazil; with a finite element method (FEM)-based Newton Raphson image reconstruction algorithm) during a decremental positive end-expiratory pressure (PEEP) trial. The patient suffered from severe acute respiratory distress syndrome as detected in the CT scan (top left) obtained at the same chest plane where the EIT electrode belt was located during the EIT examination. The panels 1-10 show regional lung hyperdistension and collapse at each PEEP step in white and blue colours, respectively. The percentages of collapse and overdistension are provided at the right side of each panel and in the diagram (bottom left). With decreasing PEEP, hyperdistension fell (green curve) and collapse rose (blue curve). The crossover point between the curves is highlighted by the red arrow. The corresponding PEEP step preceding the crossover shows the value of $17 \mathrm{~cm} \mathrm{H}_{2} \mathrm{O}$ in red in panel 4 . 

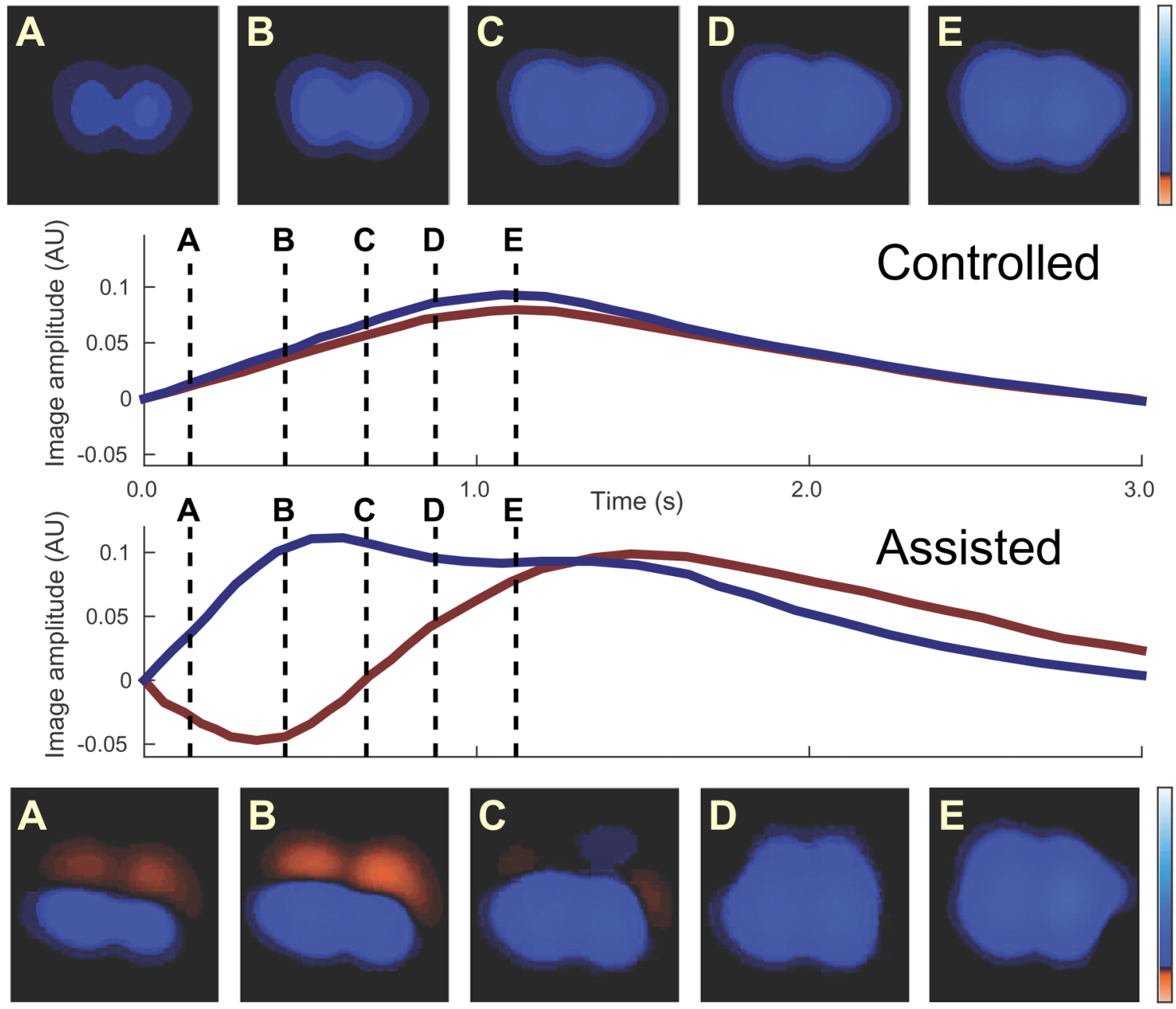

Figure 4 Ventilation distribution in a supine adult patient in the course of one tidal inflation during controlled and assisted mechanical ventilation in the pressure-controlled mode. The data were acquired with the Enlight device (Timpel, Sao Paulo, Brazil) using a finite element method (FEM)-based Newton Raphson reconstruction algorithm. The electrical impedance tomography (EIT) images show the impedance variation compared with the beginning of the respiratory cycle at five time points highlighted by dashed lines (A-E). In controlled ventilation, anterior and posterior regions inflated synchronously, as seen in the blue and red waveforms. In contrast, when the same patient was allowed to perform spontaneous efforts, the pendelluft phenomenon was detected by EIT with a volume shift from the anterior to the posterior regions attributed to differences in local driving forces and lung mechanics. The stronger posterior diaphragm excursion 'sucked' air from the anterior regions, which deflated at the beginning of inspiration, causing a transient local overdistension in the posterior regions. This excessive volume shift can be seen in the blue waveform as an overshoot (simultaneously with an undershoot in the red anterior lung waveform) before decreasing to the mechanical equilibrium with the ventilator, followed by relatively synchronous expiration. Red and blue regions in the EIT images imply a decrease and an increase in regional impedance, respectively, when compared with the beginning of inspiration.

during mechanical ventilation and providing continuous surveillance. Automatic interpretation of large sequences of EIT images will be the key to improve its daily use.

\section{Monitoring of heart activity and lung perfusion}

The major focus of EIT in this field is the real-time measurement of regional lung perfusion, although smaller studies aiming at cardiac-output measurement, heart-lung interactions and PE also exist. Lung perfusion has mostly been assessed by the amplitude of regional EIT signal pulsatility. This heartbeat-related EIT signal variation reflects the periodic changes in blood vessel dimension. Using this approach, regional hypoxic pulmonary vasoconstriction $^{83} 84$ and prostacyclin-induced vasodilation ${ }^{85}$ have been identified in patients and hyperoxic vasodilation in healthy volunteers. ${ }^{86}$ Another method, examined in mechanically ventilated patients, is based on the measurement of regional oxygen uptake by EIT. ${ }^{87}$ The only approach specifically tracking pulmonary blood flow uses the first-pass kinetics of intravenously administered hypertonic saline bolus (figure 5) and was described and validated in experimental studies. ${ }^{55} 88$

Monitoring of lung perfusion might be important in the already addressed use of EIT for guidance of ventilator therapy because it would allow ventilation/perfusion distribution mismatch to be taken into account. However, clinical validation in this field is lacking.

\section{Pulmonary function testing}

An increased demand is observed for EIT imaging in ambulatory patients, as an adjunct to conventional pulmonary function tests. In patients with COPD, ${ }^{42}{ }^{62}$ asthma ${ }^{63}$ and cystic fibrosis, ${ }^{77}$ EIT generates cross-sectional maps of the pulmonary function measures known from conventional spirometry, enabling the assessment of both spatial and temporal heterogeneity of regional lung function over time or after intervention (eg, 

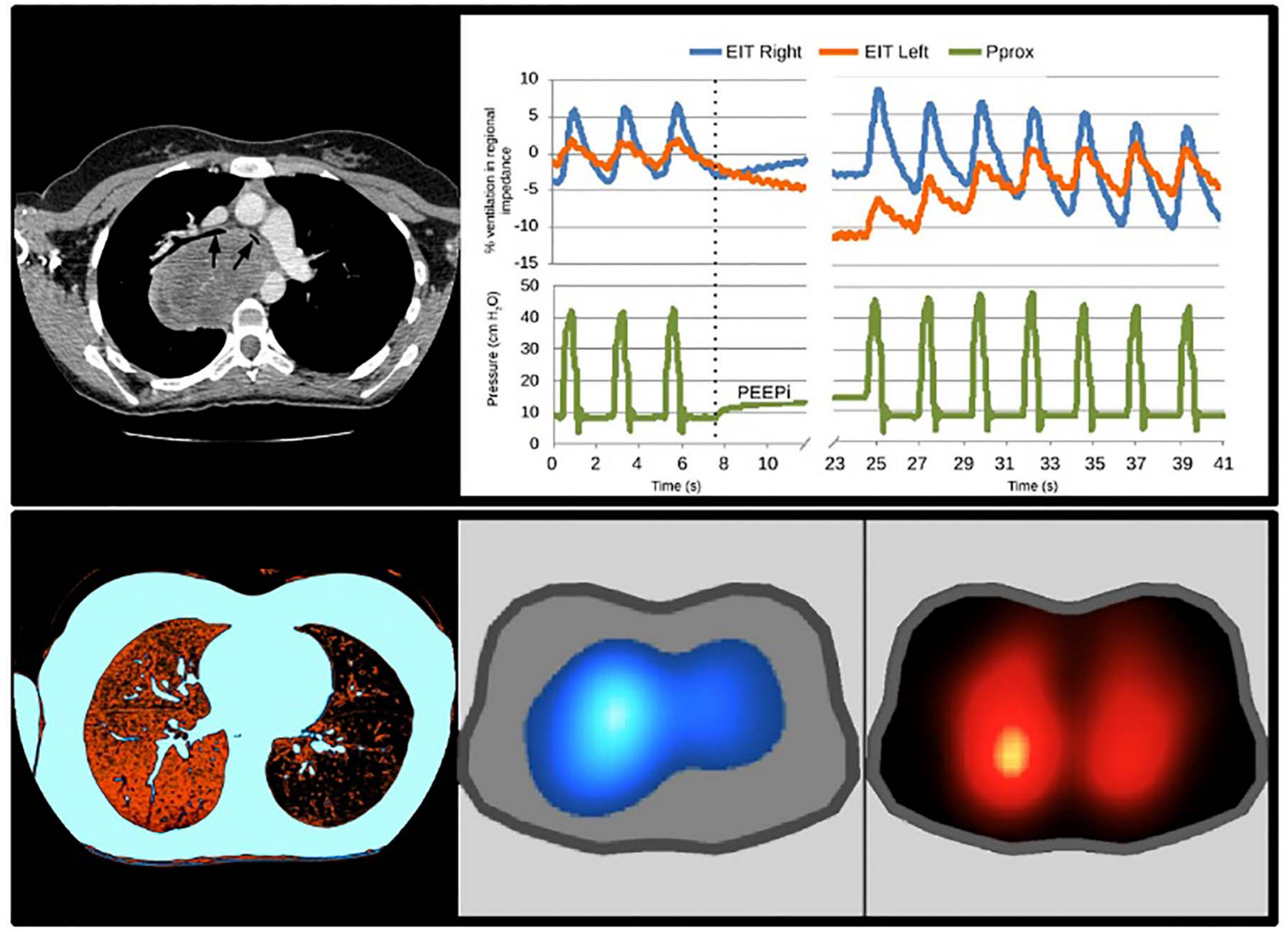

Figure 5 An adult patient with a mediastinal mass admitted to the intensive care unit with severe respiratory failure and difficult mechanical ventilation (peak inspiratory pressures $>40 \mathrm{cmH}_{2} \mathrm{O}$ ). The $\mathrm{CT}$ image suggested severe airway obstruction caused by tumour invasion, with probable obstruction of right pulmonary artery (top left). Black arrows in the top left panel show the severe obstruction of the main bronchi, more pronounced on the left. This supported the surgical plan of right-sided pneumonectomy along with tumour excision. As part of the detailed patient evaluation, an electrical impedance tomography (EIT) examination (Enlight, Timpel, Sao Paulo, Brazil; with a finite element method (FEM)-based Newton Raphson algorithm) was performed to estimate regional ventilation and perfusion. Regional EIT waveforms showed smaller ventilation amplitude in the left lung (red) in comparison to the right lung (blue). During a prolonged expiratory pause, intrinsic positive end-expiratory pressure (PEEPi) was detected in the proximal airway pressure (Pprox) signal. At the same time, an evident redistribution of air occurred: the left lung exhibited a decrease and the right lung an increase in air content. When ventilation returned, the opposite occurred, with cumulative air trapping in the left and concomitant deflation of the right lungs. A CT image, colour-coded to enhance the low lung density, demonstrated the marked air trapping in the left lung (bottom left). The functional EIT images showed the right lung to exhibit higher ventilation (bottom middle) and perfusion (bottom right) than the left lung. These findings resulted in changed surgical plans and preservation of the right lung. After the removal of the compressing mass (rhabdomyosarcoma), which was ultimately not invading the right pulmonary artery, the patient was successfully extubated 2 days later.

bronchodilation) during spontaneous tidal breathing and forced ventilation manoeuvres (figure 6). Regional pulmonary function testing by EIT might improve the patient phenotyping, the monitoring of natural history of disease and therapy effects and the prediction of clinical outcomes. Clearly, more clinical trials are needed in this field, especially those studying the relationship between the disease severity and EIT findings.

Besides the described three major fields of EIT use in adult patients, there are additional clinical situations in which EIT information has been helpful for clinical decisions (refer to EOS 7 for further information and the extensive references).

\section{CLINICAL USE OF EIT IN NEONATAL AND PAEDIATRIC PATIENTS}

By virtue of being non-invasive and radiation-free, as well as allowing respiratory monitoring independent of an endotracheal tube, EIT offers particular promise in the vulnerable population of neonatal and paediatric patients. To date, the focus of most studies has been on monitoring regional changes in lung aeration and, to a lesser extent, lung perfusion, with the aim of improving knowledge on lung physiology and better understanding the interaction between the impact of lung disease and clinical interventions on lung function.

Safe and effective guidance of mechanical ventilation in neonates, infants and children requires considering the regional volumes of the diseased lung. Consequently, most EIT studies investigating lung aeration have focused on regional changes in EELV and/or (tidal) ventilation. Studies in preterm infants with respiratory distress syndrome (RDS) receiving high-frequency ventilation showed that stepwise lung recruitment resulted in a relatively homogenous increase in EELV, with patterns similar to global volume measures. ${ }^{89}$ EIT can map the regional pressurevolume relationships of the respiratory system, measuring the extent of lung hysteresis and allowing identification of an optimal applied airway pressure (figure 7). EIT has helped show that exogenous surfactant therapy in preterm infants results in an increase and stabilisation of regional EELV (figure 7$)^{46}$ and alters the respiratory time constants. ${ }^{59}$ In conventionally ventilated children with acute lung injury, EIT could monitor regional EELV changes during stepwise recruitment. ${ }^{90}$ In this population, 
Figure 6 Electrical impedance tomography (EIT) examination of a patient aged 67 years with COPD performed during forced full expiration (Goe-MF II EIT device (CareFusion, Höchberg, Germany) with the GREIT image reconstruction). The regional EIT waveforms (bottom left) originate from four image pixels highlighted in the functional EIT ventilation image of this patient (top). The waveforms were normalised to better visualise the regional dissimilarities in lung emptying. The histogram (bottom right) shows the heterogeneity of EIT-derived pixel ratios of $\mathrm{FEV}_{1}$ and FVC. rel. $\Delta Z$, relative impedance change.
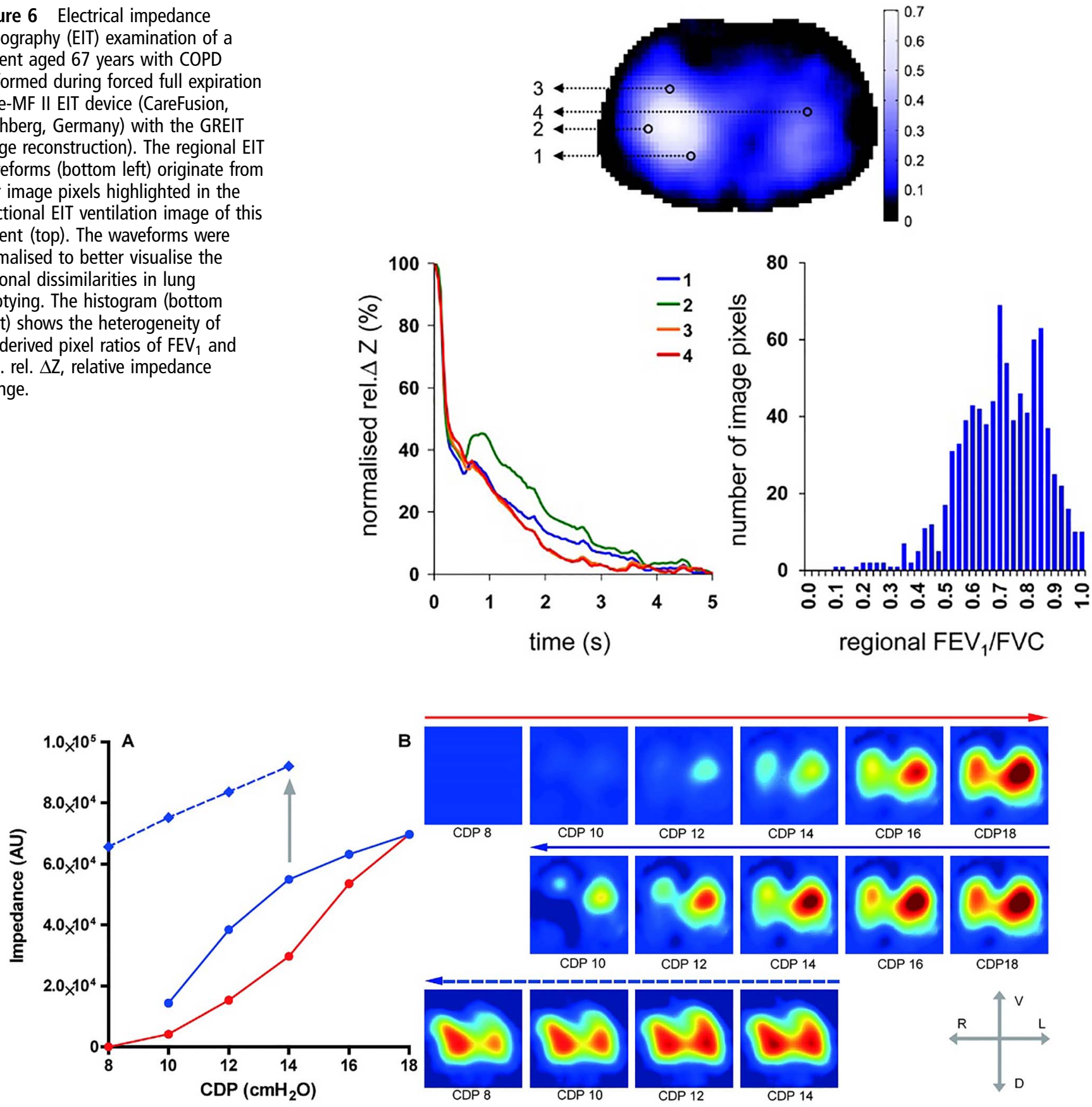

Figure 7 End-expiratory lung volume changes measured by electrical impedance tomography (EIT) (Goe-MF II EIT device (CareFusion, Höchberg, Germany) with the GREIT image reconstruction) in a preterm infant (weight $800 \mathrm{~g}$ ) with respiratory distress syndrome subjected to an oxygenation-guided lung recruitment procedure during high-frequency ventilation before and after exogenous surfactant administration. Using the impedance changes at a continuous distending pressure of $8 \mathrm{cmH}_{2} \mathrm{O}$ as the reference value, both the inflation (solid red line) and the deflation limbs (solid blue line) before and the deflation limb (dashed blue line) after surfactant treatment (grey arrow) are mapped (A). In addition, the regional impedance changes in the cross-sectional slice of the chest during each incremental and decremental pressure step are presented as functional EIT images (B). Red colour indicates a large variation and blue a small variation in impedance. Note the presence of lung hysteresis before surfactant treatment $(A)$ and the dissimilar regional changes in lung aeration (B). Also note the increase in lung aeration and its distribution after surfactant treatment and the stabilising effect on the deflation limb. $A U$, arbitrary unit; $C D P$, continuous distending pressure; $R$, right; $L$, left; $V$, ventral; $D$, dorsal.

there was clear heterogeneity in the regional volume response, with the largest increase in EELV in the dependent lung regions. Significant breath-to-breath variability in regional tidal ventilation, unrecognised using current bedside tools, was reported in a population of preterm infants receiving volume-targeted conventional ventilation, suggesting another way EIT could guide ventilator settings at the bedside. ${ }^{91}$ EIT has also been used to monitor EELV during clinical interventions, such as induction of anaesthesia, intubation and endotracheal suction. ${ }^{21} 92$

EIT studies on the effect of body positioning on regional ventilation in infants and children have challenged the physiological paradigm that ventilation is preferentially distributed towards 
the non-dependent lung. They have shown highly variable ventilation distribution. ${ }^{17-19} 93$ A positional effect can favour both the dependent and non-dependent lung regions, probably depending on factors such as the presence of underlying lung disease and/or respiratory support, initial posture, use of sedation, breathing pattern, transpulmonary pressure and age.

Asymmetrical distribution of ventilation measured by EIT can assist the clinician in diagnosing unilateral lung disease such as pneumothorax, atelectasis and malpositioning of the endotracheal tube ${ }^{94-96}$ In the short term, the use for these purposes may be the easiest method of broadly integrating EIT into the clinical environment. The results of a few studies in children with asthma and cystic fibrosis showed the potential of EIT-based regional pulmonary function testing to detect and monitor lung function heterogeneity. This is a new prospect of EIT use in the diagnostics of paediatric lung diseases that needs to be further evaluated.

To date, studies in infants and children on EIT-derived lung perfusion have been limited. A study in preterm infants showed that measuring changes in pulmonary blood volume by EIT was feasible and that the changes were greater in the non-dependent lung. ${ }^{97}$ EIT has been used to demonstrate a decrease in global and regional pulmonary blood flow following ventricular septum defect repair in children. ${ }^{98}$

Validation studies in infants and children are limited, because comparative monitoring with $\mathrm{CT}$ and radionuclide scanning is often not feasible or safe. To date, functional EIT images have mainly been compared with chest radiography, showing a similar loss in aeration. ${ }^{23} 9495$ One study in preterm infants with RDS showed that the changes measured in the crosssectional slice by EIT are representative of changes in the whole lung measured by respiratory inductance plethysmography. ${ }^{99}$

Further details on the use of EIT in the neonatal and paediatric populations with tables summarising the clinical issues monitored by EIT can be found in EOS 8 .

\section{FUTURE DIRECTION IN EIT DEVELOPMENT, EVALUATION AND USE}

The priority of EIT research is to establish this method in clinical practice. ${ }^{100}$ This process requires the identification of relevant unmet clinical needs and remaining deficits in EIT technology and clinical validation. We provide this information in EOS 9 together with the recommendations for future steps needed.

\section{CONCLUSION}

We are convinced that EIT is at an important stage of its development, which bears both opportunities and risks. EIT has the potential of bringing new possibilities to the management of mechanically ventilated patients and patients with chronic lung diseases. Common standardised techniques, terminology, coordination and consensus on EIT application with large multicenter clinical trials are needed to promote the clinical use. We hope to have provided most of this essential information in this article.

\section{Author affiliations}

${ }^{1}$ Department of Anesthesiology and Intensive Care Medicine, University Medical Center Schleswig-Holstein, Campus Kiel, Kiel, Germany

${ }^{2}$ Pulmonary Division, Heart Institute (InCor), Hospital das Clínicas da Faculdade de Medicina da Universidade de São Paulo, São Paulo, Brazil

${ }^{3}$ Department of Neonatology, Emma Children's Hospital, Academic Medical Center, Amsterdam, The Netherlands

${ }^{4}$ Neonatal Research, Murdoch Childrens Research Institute, Parkville, Victoria, Australia

${ }^{5}$ Institute of Technical Medicine, Furtwangen University, Villingen-Schwenningen, Germany
}

${ }^{6}$ Fraunhofer Project Group for Automation in Medicine and Biotechnology PAMB, Mannheim, Germany

${ }^{7}$ Department of Anesthesiology, University Medical Center of the Johannes Gutenberg-University, Mainz, Germany

${ }^{8}$ Department of Systems and Computer Engineering, Carleton University, Ottawa, Ontario, Canada

${ }^{9}$ Swisstom AG, Landquart, Switzerland

${ }^{10}$ Dräger Medical GmbH, Lübeck, Germany

${ }^{11}$ Department of Anesthesiology and Intensive Care Medicine, Sahlgrenska University Hospital, Gothenburg, Sweden

${ }^{12}$ Department of Anesthesia, Critical Care and Emergency, Fondazione IRCCS Ca' Granda Ospedale Maggiore Policlinico, Milan, Italy

${ }^{13}$ Department of Adult Critical Care, Guy's and St Thomas' NHS Foundation Trust, London, UK

${ }^{14}$ Paediatric Critical Care Research Group, Mater Research University of Queensland, South Brisbane, Australia

${ }^{15}$ Children's Hospital Traunstein, Ludwig Maximilian's University, Munich, Germany

${ }^{16}$ Department of Adult Intensive Care, Erasmus MC, Rotterdam, The Netherlands

${ }^{17}$ Philips Chair for Medical Information Technology, Helmholtz-Institute for

Biomedical Engineering, RWTH Aachen University, Aachen, Germany

Acknowledgements We acknowledge the inputs from Eddy Fan, William RB Lionheart, Thomas Riedel, Peter C Rimensberger, Fernando Suarez Sipmann, Norbert Weiler and Hermann Wrigge.

Collaborators TRanslational EIT developmeNt study (TREND) group: Eddy Fan; William RB Lionheart; Thomas Riedel; Peter C Rimensberger; Fernando Suarez Sipmann; Norbert Weiler and Hermann Wrigge.

Contributors Writing: IF, AA, MBPA, AHvK, DGT, ZZ, BG, MB, HG, SHB and ET with input from OS, TM, VT, LC, AS, GKW, DG and SL. Revising and approval of the manuscript: all authors and collaborators of the TREND study group.

Competing interests IF: Grants from The European Union's 7th Framework Programme for Research and Technological Development (WELCOME, Grant No. 611223) and from The European Union's Framework Programme for Research and Innovation Horizon 2020 (CRADL, Grant No. 668259), personal fees from Dräger, outside the submitted work. MBPA: Grants from Dixtal/Philips and Timpel SA, outside the submitted work. AHvK: non-financial support from CareFusion, outside the submitted work. DGT: Goe-MF II EIT system provided by CareFusion for unrestricted research use, two Swisstom Pioneer EIT systems and consumables fully purchased from the manufacturer, unrestricted assistance in customising research software for specific research needs by Swisstom. ZZ: Grant from the German Federal Ministry of Education and Research (MOSES, Grant No. 03FH03813), personal fees from Dräger Medical, outside the submitted work. BG: Personal fees from Swisstom, outside the submitted work. SHB: Co-founder, employee and Chief Medical Officer of Swisstom AG, inventor of several EIT-related patents and patent applications owned by Swisstom AG and Timpel SA. ET: Employee of Dräger; several EIT-related patents pending and issued to Dräger. OS: Personal fees and non-financial support from Dräger Medical, outside the submitted work; owner of an issued patent EP 228009A1. VT: Personal fees from Timpel, outside the submitted work. DG: Personal fees from Dräger Medical, outside the submitted work. SL: Grants, personal fees and non-financial support from Dräger Medical, grants and non-financial support from Philips Research, grants and non-financial support from BMBF (private/public partnership project with Weinmann $\mathrm{GmbH}$ ), grants and non-financial support from BMWi (public/private partnership ZIM project with Fritz Stephan $\mathrm{GmbH}$ ), outside the submitted work; several patents pending, licensed and issued to Dräger Medical AG \& Co KGaA.

Provenance and peer review Not commissioned; externally peer reviewed.

Open Access This is an Open Access article distributed in accordance with the Creative Commons Attribution Non Commercial (CC BY-NC 4.0) license, which permits others to distribute, remix, adapt, build upon this work non-commercially, and license their derivative works on different terms, provided the original work is properly cited and the use is non-commercial. See: http://creativecommons.org/ licenses/by-nc/4.0/

\section{REFERENCES}

1 Barber D, Brown B. Applied potential tomography. J Phys E Sci Instrum 1984; 17:723-33.

2 Bodenstein M, David M, Markstaller K. Principles of electrical impedance tomography and its clinical application. Crit Care Med 2009;37:713-24.

3 Costa EL, Lima RG, Amato MB. Electrical impedance tomography. Curr Opin Crit Care 2009;15:18-24.

4 Frerichs I. Electrical impedance tomography (EIT) in applications related to lung and ventilation: a review of experimental and clinical activities. Physiol Meas 2000;21:R1-21.

5 Frerichs I, Becher T, Weiler N. Electrical impedance tomography imaging of the cardiopulmonary system. Curr Opin Crit Care 2014;20:323-32. 
6 Leonhardt S, Lachmann B. Electrical impedance tomography: the holy grail of ventilation and perfusion monitoring? Intensive Care Med 2012;38:1917-29.

7 Lundin S, Stenqvist 0 . Electrical impedance tomography: potentials and pitfalls. Curr Opin Crit Care 2012;18:35-41.

8 Moerer O, Hahn G, Quintel M. Lung impedance measurements to monitor alveolar ventilation. Curr Opin Crit Care 2011;17:260-7.

9 Muders $\mathrm{T}$, Luepschen $\mathrm{H}$, Putensen $\mathrm{C}$. Impedance tomography as a new monitoring technique. Curr Opin Crit Care 2010;16:269-75.

10 Pillow JJ, Frerichs I, Stocks J. Lung function tests in neonates and infants with chronic lung disease: global and regional ventilation inhomogeneity. Pediatr Pulmonol 2006;41:105-21.

11 Riedel T, Frerichs I. Electrical impedance tomography. Eur Respir Mon 2010:47:195-205

12 Frerichs I, Hahn G, Hellige G. Thoracic electrical impedance tomographic measurements during volume controlled ventilation-effects of tidal volume and positive end-expiratory pressure. IEEE Trans Med Imaging 1999;18:764-73.

13 Karsten J, Stueber T, Voigt N, et al. Influence of different electrode belt positions on electrical impedance tomography imaging of regional ventilation: a prospective observational study. Crit Care 2016;20:3.

14 Reifferscheid F, Elke G, Pulletz $\mathrm{S}$, et al. Regional ventilation distribution determined by electrical impedance tomography: reproducibility and effects of posture and chest plane. Respirology 2011;16:523-31.

15 Krueger-Ziolek S, Schullcke B, Kretschmer J, et al. Positioning of electrode plane systematically influences EIT imaging. Physiol Meas 2015;36:1109-18.

16 Frerichs I, Braun P, Dudykevych T, et al. Distribution of ventilation in young and elderly adults determined by electrical impedance tomography. Resp Physiol Neurobiol 2004;143:63-75

17 Frerichs I, Schiffmann $\mathrm{H}$, Oehler $\mathrm{R}$, et al. Distribution of lung ventilation in spontaneously breathing neonates lying in different body positions. Intensive Care Med 2003:29:787-94.

18 Heinrich S, Schiffmann H, Frerichs A, et al. Body and head position effects on regional lung ventilation in infants: an electrical impedance tomography study. Intensive Care Med 2006:32:1392-8.

19 Lupton-Smith AR, Argent AC, Rimensberger PC, et al. Challenging a paradigm: positional changes in ventilation distribution are highly variable in healthy infants and children. Pediatr Pulmonol 2014;49:764-71.

20 Frerichs I, Hahn G, Golisch W, et al. Monitoring perioperative changes in distribution of pulmonary ventilation by functional electrical impedance tomography. Acta Anaesthesiol Scand 1998:42:721-6.

21 Humphreys S, Pham TM, Stocker $C$, et al. The effect of induction of anesthesia and intubation on end-expiratory lung level and regional ventilation distribution in cardiac children. Paediatr Anaesth 2011:21:887-93.

22 Yoshida T, Torsani V, Gomes S, et al. Spontaneous effort causes occult pendelluft during mechanical ventilation. Am J Respir Crit Care Med 2013;188:1420-7.

23 Frerichs I, Schiffmann $\mathrm{H}, \mathrm{Hahn} \mathrm{G}$, et al. Non-invasive radiation-free monitoring of regional lung ventilation in critically ill infants. Intensive Care Med 2001;27:1385-94

24 Blankman P, Hasan D, van Mourik MS, et al. Ventilation distribution measured with EIT at varying levels of pressure support and neurally adjusted ventilatory assist in patients with ALI. Intensive Care Med 2013;39:1057-62.

25 Mauri T, Bellani G, Confalonieri A, et al. Topographic distribution of tidal ventilation in acute respiratory distress syndrome: effects of positive end-expiratory pressure and pressure support. Crit Care Med 2013;41:1664-73.

26 Rabbani KS, Kabir AM. Studies on the effect of the third dimension on a two-dimensional electrical impedance tomography system. Clin Phys Physiol Meas 1991;12:393-402

27 Lionheart WR. EIT reconstruction algorithms: pitfalls, challenges and recent developments. Physiol Meas 2004;25:125-42.

28 Yasin M, Böhm S, Gaggero PO, et al. Evaluation of EIT system performance. Physiol Meas 2011;32:851-65.

29 Frerichs I, Dargaville PA, Dudykevych T, et al. Electrical impedance tomography: a method for monitoring regional lung aeration and tidal volume distribution? Intensive Care Med 2003;29:2312-16.

30 Grivans C, Lundin S, Stenqvist O, et al. Positive end-expiratory pressure-induced changes in end-expiratory lung volume measured by spirometry and electric impedance tomography. Acta Anaesthesio/ Scand 2011;55:1068-77.

31 Becher TH, Bui S, Zick G, et al. Assessment of respiratory system compliance with electrical impedance tomography using a positive end-expiratory pressure wave maneuver during pressure support ventilation: a pilot clinical study. Crit Care 2014; 18:679.

32 Geddes LA, Baker LE. The specific resistance of biological material - a compendium of data for the biomedical engineer and physiologist. Med Biol Eng 1967:5:271-93.

33 Vogt B, Mendes L, Chouvarda I, et al. Influence of torso and arm positions on chest examinations by electrical impedance tomography. Physiol Meas 2016;37:904-21.

34 Frerichs I, Pulletz S, Elke G, et al. Patient examinations using electrical impedance tomography-sources of interference in the intensive care unit. Physiol Meas 2011;32:L1-L10.
35 Pulletz S, van Genderingen HR, Schmitz G, et al. Comparison of different methods to define regions of interest for evaluation of regional lung ventilation by EIT. Physiol Meas 2006;27:S115-27.

36 Becher $T$, Vogt $B$, Kott $M$, et al. Functional regions of interest in electrical impedance tomography: a secondary analysis of two clinical studies. PLoS One 2016;11:e0152267.

37 Frerichs I, Dargaville PA, van Genderingen $\mathrm{H}$, et al. Lung volume recruitment after surfactant administration modifies spatial distribution of ventilation. Am J Respir Crit Care Med 2006;174:772-9.

38 Lowhagen K, Lundin S, Stenqvist O. Regional intratidal gas distribution in acute lung injury and acute respiratory distress syndrome-assessed by electric impedance tomography. Minerva Anestesiol 2010;76:1024-35.

39 Bhatia R, Schmölzer GM, Davis PG, et al. Electrical impedance tomography can rapidly detect small pneumothoraces in surfactant-depleted piglets. Intensive Care Med 2012;38:308-15.

40 Becher $T$, Kott M, Schädler D, et al. Influence of tidal volume on ventilation inhomogeneity assessed by electrical impedance tomography during controlled mechanical ventilation. Physiol Meas 2015;36:1137-46.

41 Meier $\mathrm{T}$, Luepschen $\mathrm{H}$, Karsten J, et al. Assessment of regional lung recruitment and derecruitment during a PEEP trial based on electrical impedance tomography. Intensive Care Med 2008:34:543-50.

42 Vogt B, Pulletz S, Elke G, et al. Spatial and temporal heterogeneity of regional lung ventilation determined by electrical impedance tomography during pulmonary function testing. J App/ Physiol 2012;113:1154-61.

43 Frerichs I, Dudykevych T, Hinz J, et al. Gravity effects on regional lung ventilation determined by functional EIT during parabolic flights. J App/ Physiol 2001;91:39-50.

44 Pulletz $\mathrm{S}$, Kott M, Elke $\mathrm{G}$, et al. Dynamics of regional lung aeration determined by electrical impedance tomography in patients with acute respiratory distress syndrome. Multidiscip Respir Med 2012;7:44.

45 Frerichs I, Dargaville PA, Rimensberger PC. Regional respiratory inflation and deflation pressure-volume curves determined by electrical impedance tomography. Physiol Meas 2013:34:567-77.

46 Miedema $\mathrm{M}$, de Jongh $\mathrm{FH}$, Frerichs I, et al. Changes in lung volume and ventilation during surfactant treatment in ventilated preterm infants. Am J Respir Crit Care Med 2011;184:100-5.

47 Pulletz S, Adler A, Kott M, et al. Regional lung opening and closing pressures in patients with acute lung injury. J Crit Care 2012;27:323.e11-8.

48 Gómez-Laberge C, Rettig JS, Smallwood CD, et al. Interaction of dependent and non-dependent regions of the acutely injured lung during a stepwise recruitment manoeuvre. Physiol Meas 2013;34:163-77.

49 Zhao Z, Möller K, Steinmann D, et al. Evaluation of an electrical impedance tomography-based global inhomogeneity index for pulmonary ventilation distribution. Intensive Care Med 2009:35:1900-6.

50 Frerichs I, Achtzehn U, Pechmann A, et al. High-frequency oscillatory ventilation in patients with acute exacerbation of chronic obstructive pulmonary disease. J Crit Care 2012;27:172-81.

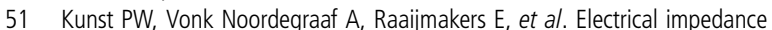
tomography in the assessment of extravascular lung water in noncardiogenic acute respiratory failure. Chest 1999;116:1695-702.

52 Zick G, Elke G, Becher $T$, et al. Effect of PEEP and tidal volume on ventilation distribution and end-expiratory lung volume: a prospective experimental animal and pilot clinical study. PLoS One 2013;8:e72675.

53 Tingay DG, Wallace MJ, Bhatia $R$, et al. Surfactant before the first inflation at birth improves spatial distribution of ventilation and reduces lung injury in preterm lambs. J App/ Physiol 2014;116:251-8.

54 Grychtol B, Elke G, Meybohm P, et al. Functional validation and comparison framework for EIT lung imaging. PLoS One 2014;9:e103045.

55 Borges JB, Suarez-Sipmann F, Bohm SH, et al. Regional lung perfusion estimated by electrical impedance tomography in a piglet model of lung collapse. J App/ Physiol 2012;112:225-36.

56 Grychtol B, Wolf GK, Arnold JH. Differences in regional pulmonary pressure-impedance curves before and after lung injury assessed with a novel algorithm. Physiol Meas 2009;30:S137-48.

57 Dargaville PA, Rimensberger PC, Frerichs I. Regional tidal ventilation and compliance during a stepwise vital capacity manoeuvre. Intensive Care Med 2010;36:1953-61.

58 Wolf GK, Gómez-Laberge C, Rettig JS, et al. Mechanical ventilation guided by electrical impedance tomography in experimental acute lung injury. Crit Care Med 2013:41:1296-304.

59 Miedema $\mathrm{M}$, de Jongh $\mathrm{FH}$, Frerichs I, et al. Regional respiratory time constants during lung recruitment in high-frequency oscillatory ventilated preterm infants. Intensive Care Med 2012:38:294-9.

60 Riedel T, Kyburz M, Latzin P, et al. Regional and overall ventilation inhomogeneities in preterm and term-born infants. Intensive Care Med 2009:35:144-51.

61 Wrigge $H$, Zinserling J, Muders $T$, et al. Electrical impedance tomography compared with thoracic computed tomography during a slow inflation maneuver in experimental models of lung injury. Crit Care Med 2008;36:903-9. 
62 Vogt B, Zhao Z, Zabel P, et al. Regional lung response to bronchodilator reversibility testing determined by electrical impedance tomography in chronic obstructive pulmonary disease. Am J Physiol Lung Cell Mol Physiol 2016;311: L8-L19.

63 Frerichs I, Zhao Z, Becher T, et al. Regional lung function determined by electrical impedance tomography during bronchodilator reversibility testing in patients with asthma. Physiol Meas 2016;37:698-712.

64 Frerichs I, Hinz J, Herrmann P, et al. Detection of local lung air content by electrical impedance tomography compared with electron beam CT. J Appl Physiol 2002;93:660-6.

65 Elke G, Fuld MK, Halaweish AF, et al. Quantification of ventilation distribution in regional lung injury by electrical impedance tomography and xenon computed tomography. Physiol Meas 2013;34:1303-18.

66 Victorino JA, Borges JB, Okamoto VN, et al. Imbalances in regional lung ventilation: a validation study on electrical impedance tomography. Am J Respir Crit Care Med 2004;169:791-800.

67 Hinz J, Neumann P, Dudykevych T, et al. Regional ventilation by electrical impedance tomography: a comparison with ventilation scintigraphy in pigs. Chest 2003:124:314-22.

68 Richard JC, Pouzot C, Gros A, et al. Electrical impedance tomography compared to positron emission tomography for the measurement of regional lung ventilation: an experimental study. Crit Care 2009;13:R82.

69 Shi C, Boehme S, Bentley AH, et al. Assessment of regional ventilation distribution: comparison of vibration response imaging (VRI) with electrical impedance tomography (EIT). PLOS One 2014;9:e86638.

70 Hinz J, Moerer $\mathrm{O}$, Neumann P, et al. Effect of positive end-expiratory-pressure on regional ventilation in patients with acute lung injury evaluated by electrical impedance tomography. Eur I Anaesthesiol 2005;22:817-25

71 Coulombe N, Gagnon H, Marquis F, et al. A parametric model of the relationship between EIT and total lung volume. Physiol Meas 2005;26:401-11.

72 Odenstedt $\mathrm{H}$, Lindgren $\mathrm{S}$, Olegård $\mathrm{C}$, et al. Slow moderate pressure recruitment maneuver minimizes negative circulatory and lung mechanic side effects: evaluation of recruitment maneuvers using electric impedance tomography. Intensive Care Med 2005:31:1706-14.

73 Costa EL, Borges JB, Melo A, et al. Bedside estimation of recruitable alveolar collapse and hyperdistension by electrical impedance tomography. Intensive Care Med 2009;35:1132-7.

74 Karsten J, Grusnick C, Paarmann H, et al. Positive end-expiratory pressure titration at bedside using electrical impedance tomography in post-operative cardiac surgery patients. Acta Anaesthesiol Scand 2015;59:723-32.

75 Blankman P, Hasan D, Erik G, et al. Detection of 'best' positive end-expiratory pressure derived from electrical impedance tomography parameters during a decremental positive end-expiratory pressure trial. Crit Care 2014;18:R95.

76 Serrano RE, de LB, Casas O, et al. Use of electrical impedance tomography (EIT) for the assessment of unilateral pulmonary function. Physiol Meas 2002;23:211-20.

77 Zhao Z, Müller-Lisse U, Frerichs I, et al. Regional airway obstruction in cystic fibrosis determined by electrical impedance tomography in comparison with high resolution CT. Physiol Meas 2013;34:N107-14.

78 Spaeth J, Daume K, Goebel U, et al. Increasing positive end-expiratory pressure (re-)improves intraoperative respiratory mechanics and lung ventilation after prone positioning. Br J Anaesth 2016;116:838-46.

79 Costa EL, Chaves CN, Gomes S, et al. Real-time detection of pneumothorax using electrical impedance tomography. Crit Care Med 2008;36:1230-8.

80 Tingay DG, Copnell B, Grant CA, et al. The effect of endotracheal suction on regional tidal ventilation and end-expiratory lung volume. Intensive Care Med 2010;36:888-96.
81 Alves $\mathrm{SH}$, Amato MB, Terra RM, et al. Lung reaeration and reventilation after aspiration of pleural effusions. A study using electrical impedance tomography. Ann Am Thorac Soc 2014;11:186-91.

82 Pulletz S, Elke G, Zick G, et al. Performance of electrical impedance tomography in detecting regional tidal volumes during one-lung ventilation. Acta Anaesthesiol Scand 2008;52:1131-9.

83 Frerichs I, Pulletz S, Elke G, et al. Assessment of changes in distribution of lung perfusion by electrical impedance tomography. Respiration 2009;77:282-91.

84 Vonk Noordegraaf A, Kunst PW, Janse A, et al. Pulmonary perfusion measured by means of electrical impedance tomography. Physiol Meas 1998;19:263-73.

85 Smit HJ, Vonk Noordegraaf A, Roeleveld RJ, et al. Epoprostenol-induced pulmonary vasodilatation in patients with pulmonary hypertension measured by electrical impedance tomography. Physiol Meas 2002;23:237-43.

86 Li Y, Tesselaar E, Borges JB, et al. Hyperoxia affects the regional pulmonary ventilation/perfusion ratio: an electrical impedance tomography study. Acta Anaesthesiol Scand 2014;58:716-25.

87 Elke G, Pulletz S, Schädler D, et al. Measurement of regional pulmonary oxygen uptake - novel approach using electrical impedance tomography. Physiol Meas 2011:32:877-86.

88 Frerichs I, Hinz J, Herrmann P, et al. Regional lung perfusion as determined by electrical impedance tomography in comparison with electron beam $\mathrm{CT}$ imaging. IEEE Trans Med Imaging 2002;21:646-52.

89 Miedema M, de Jongh FH, Frerichs I, et al. Changes in lung volume and ventilation during lung recruitment in high-frequency ventilated preterm infants with respiratory distress syndrome. J Pediatr 2011;159:199-205.e2.

90 Wolf GK, Gómez-Laberge C, Kheir JN, et al. Reversal of dependent lung collapse predicts response to lung recruitment in children with early acute lung injury. Pediatr Crit Care Med 2012;13:509-15.

91 Armstrong RK, Carlisle HR, Davis PG, et al. Distribution of tidal ventilation during volume-targeted ventilation is variable and influenced by age in the preterm lung. Intensive Care Med 2011;37:839-46.

92 van Veenendaal MB, Miedema $\mathrm{M}$, de Jongh $\mathrm{FH}$, et al. Effect of closed endotracheal suction in high-frequency ventilated premature infants measured with electrical impedance tomography. Intensive Care Med 2009;35:2130-4.

93 Schibler A, Yuill M, Parsley C, et al. Regional ventilation distribution in non-sedated spontaneously breathing newborns and adults is not different. Pediatr Pulmonol 2009:44:851-8

94 Miedema M, Frerichs I, de Jongh FH, et al. Pneumothorax in a preterm infant monitored by electrical impedance tomography: a case report. Neonatology 2011:99:10-13

95 van der Burg PS, Miedema $\mathrm{M}$, de Jongh $\mathrm{FH}$, et al. Unilateral atelectasis in a preterm infant monitored with electrical impedance tomography: a case report. Eur J Pediatr 2014;173:1715-17.

96 Steinmann D, Engehausen M, Stiller B, et al. Electrical impedance tomography for verification of correct endotracheal tube placement in paediatric patients: a feasibility study. Acta Anaesthesio/ Scand 2013;57:881-7.

97 Carlisle HR, Armstrong RK, Davis PG, et al. Regional distribution of blood volume within the preterm infant thorax during synchronised mechanical ventilation. Intensive Care Med 2010;36:2101-8.

98 Schibler A, Pham TM, Moray AA, et al. Ventilation and cardiac related impedance changes in children undergoing corrective open heart surgery. Physiol Meas 2013;34:1319-27.

99 van der Burg PS, Miedema M, de Jongh FH, et al. Cross-sectional changes in lung volume measured by electrical impedance tomography are representative for the whole lung in ventilated preterm infants. Crit Care Med 2014;42:1524-30.

100 Adler A, Amato MB, Arnold JH, et al. Whither lung EIT: where are we, where do we want to go and what do we need to get there? Physiol Meas 2012;33:679-94. 